employed. This, it is claimed, has been achieved. Given two persons sufficiently interested in coordinating the material relating to an important problem, and ready to devote to it one full evening a week, the Committee will undertake to help them in elucidating the various aspects of the problem and in bringing together the organisations concerned. The Research Co-ordination Committee has been fortunate in obtaining the co-operation of many organisations interested in various aspects of the housing question. Among these are the Housing Centre, Architectural Association, Modern Architectural Research Association, Architects and Technicians Organisation, Society of Women Estate Managers, Kitchen Planning Centre, Women's Gas Council, Institute of Sociology, etc. The Building Research Station of the Department of Scientific and Industrial Research and the Housing Section of the Ministry of Health have also provided assistance.

\section{Lighting and Heating Research}

A Conference on lighting, space heating and hot water supply in low-cost housing, arranged by the Housing Centre, 13 Suffolk Street, S.W.1, was held on May 25 and 26. In the opening address, Lord Elton referred to cheapness, efficiency and health requirements as the main directives in modern lowcost house building and contrasted them with the durability, dignity and individuality of the Tudor period. In the discussion that followed, Prof. Patrick Abercrombie, who was in the chair, pointed out that standardisation can be applied to desirable as well as undesirable features, and other contributors suggested that perhaps dignity and individuality can now be transferred from the individual house to a planned estate as a whole. Sir Richard Paget, in his address as chairman of the business part of the Conference, gave a broad view of some of the avenues opened by scientific research in the utilisation of our national fuel assets, and pointed out several cases of present wastage. He directed attention to Sir Richard Gregory's remarks at the Royal Institution on the mission of science in the changing world of to-day. $\mathrm{He}$ also stressed the urgent need of an impartial investigation of the monetary system, and ended by pointing out the value of technical conferences in bringing together experts and enabling them to synthesise their ideas into one connected whole.

THE relative merits of gas, electricity and other forms of heating were brought out in a series of papers contributed by the British Commercial Gas Association, British Electrical Development Association, Coal Utilization Council, London and Counties Coke Association and by other organisations and individual specialists. The convergence upon a common problem of these diverse interests has been a valuable feature of the Conference. The need for an impartial body to collect and collate the data supplied by the various parties was brought out, and both the Housing Centre and the Research Coordination Committee have expressed their willingness to help in this work. The immediate task of such a body would be, first, to find out what the consumer actually uses and is likely to expect with an increased standard of living and, secondly, how far his requirements can be satisfied with existing methods and appliances, or such improved forms as the advance in technique renders possible.

\section{Radium Research at Birmingham}

For some time the Physics Department of the University of Birmingham has had charge of $0.5 \mathrm{gm}$. of radium, which has been used for supplying local hospitals with radon. This radium, which belonged to the Radium Commission, has recently been allotted to the General Hospital of the City for a special purpose. It therefore appeared likely that the Radon Laboratory of the Department of Physies at the University would be put out of action. Thereupon Sir Gilbert Barling issued an appeal for a fund to provide the University with a supply of radium of its own. The appeal met with a most generous response, and with the accruing money it is proposed to buy for the University $1 \mathrm{gm}$. of radium, so that the Radon Laboratory will be able to continue to supply radon to hospitals as before, and the Physics Department will have radium available for scientific research. The Pro-Chancellor (Mr. Walter Barrow) has expressed on behalf of the University his warmest thanks to Sir Gilbert Barling for his energy and initiative and to the donors for their generous response.

\section{Conference on Atmospheric Pollution}

THE half-yearly Conference of representatives of local authorities and other organisations co-operating with the Department of Scientific and Industrial Research in the investigation of atmospheric pollution was held in the offices of the Department on May 25. The Conference received from Dr. G. M. B. Dobson, chairman of the Atmospheric Pollution Research Committee, a report on the progress of research. $\mathrm{He}$ announced that the Committee has decided to undertake an intensive survey of the pollution in and around an industrial centre and has selected the city of Leicester, the geographical position of which in relation to the surrounding country and neighbouring centres of population appears to render it particularly suitable. The Conference noted with interest that the London County Council has intimated that it is extending its investigations and that it is arranging for observations at a rural institution and a seaside institution belonging to it. Reports from Glasgow and from Sheffield and Rotherham were presented on comparative determinations of sulphur in filtered and unfiltered air. Measures for reducing pollution due to the emission of ash and grit from chimneys were also discussed. At its previous meeting, the Conference considered a proposal by the London County Council that the machinery of the Conference might be used to secure financial contributions for investigations into means for reducing this type of pollution. A committee, which was appointed to meet representatives of the Department for the discussion of practical measures, presented a report for discussion by the Conference. 